\title{
MANAJEMEN PERTUNJUKAN DALAM UJIAN TUGAS AKHIR PEMENTASAN KARYA TARI
}

\author{
Suroto ${ }^{1}$, Supriadi ${ }^{2}$, M. Nurhadi ${ }^{3}$ \\ Fakultas Seni Pertunjukan, Institut Seni Indonesia Surakarta \\ Email: surotopincuk@gmail.com, ${ }^{1}$ \\ Email: sindujupri@gmail.com, ${ }^{2}$ \\ Email: nurhadinurhadi765@gmail.com ${ }^{3}$
}

\begin{abstract}
The research entitled Performance Laboratory Management in the Final Project Performance of Dance Works takes the object of staging dance works from students who take dance creation final projects. The purpose of this research is to explain the role and process of stage management in the implementation of dance performances in the Final Project Examination for S-1 Dance. To achieve this goal, researchers need to apply the principles of performing arts management, including design, organization, leadership, and supervision. The results achieved in this study are a description of performance governance that runs smoothly, effectively, and on time. Dance creators, dancers, artistic supporters (make-up and clothing, set/property, lighting), music (sound system) are able to work together in accordance with their respective artistic designs so that they can be well appreciated by the test team and the audience.
\end{abstract}

Keywords: governance, laboratory, performance, management, dance.

\section{Pendahuluan}

Tugas Akhir merupakan karya puncak dan monumental bagi mahasiswa sebagai tolok ukur keberhasilan dalam menyelesaikan studinya. Tugas Akhir bagi mahasiswa S-1 Prodi Tari merupakan penelitian karya ilmiah dalam bentuk pilihan kompetensi penulisan skripsi, kepenarian, atau penciptaan karya seni (tari). Penelitian ini akan memfokuskan pada kegiatan manajemen (pengelolaan) pementasan untuk mahasiswa yang mengambil tugas akhir pilihan kompetensi kepenarian dan penciptaan karya tari (koreografi).

Penilaian kompetensi penciptaan karya tari yang utama koreografi sedangkan untuk kompetensi kepenarian adalah penyajian karya tari yang sudah ada. Penilaian kedua kompetensi tersebut juga didukung oleh unsur seni pertunjukan, antara lain; rias, busana, tata panggung, perangkat gamelan/musik, lighting, dan property yang digunakan (Tim
Penyusun, Panduan Tugas Akhir Fakultas Seni Pertunjukan, Surakarta : ISI Press, edisi IV tahun 2019, hal: 39-40).

Subyek penelitian adalah mahasiswa yang maju ujian tugas akhir pada tanggal 5 Nopember 2020. Tempat presentasi karya (pementasan) adalah di Laboratorium Fakultas Seni Pertunjukan (FSP) Teater Kecil.

Pengelolaan laboratorium pertunjukan untuk Tugas Akhir bagi mahasiswa Program Studi S-1 Tari ini menggunakan pendekatan manajemen atau tata kelola pertunjukan yang mempertimbangkan aspek manajemen produksi, manajemen panggung, dan prinsip penciptaan seni.

Manajemen dalam seni pertunjukan sangat penting mengingat bahwa para pegiat seni pertunjukan dalam sebuah produksi seni yang dikedepankan biasanya nilai-nilai artistik. Sehingga produk seni pertunjukan memerlukan jembatan untuk dapat berhubungan dengan penonton maupun penikmat seni. Dan jembatan 
tersebut adalah manajemen panggung.

Manajemen dalam pertunjukan bertujuan agar orang atau kelompok bekerja secara efisien untuk mencapai hasil yang diharapkan, tercapai ketenangan, kelancaran, dan keberlangsungan pertunjukan (Hasibuan, 2007). Pengelolaan ini untuk mencapai sasaran tertentu (Soedarso SP, 2006) tetapi juga mempertimbangkan prinsip penciptaan seni yang mengutamakan aspek estetiknya.

Penelitian ini mendeskripsikan tentang peran manajemen seni pertunjukan dan proses pengelolaan laboratorium seni pertunjukan dalam pelaksanaan manajemen panggung untuk Ujian Tugas akhir pertunjukan tari.

\section{Metode Penelitian}

Subyek penelitian adalah mahasiswa yang ujian tugas akhir pertunjukan tari pada tanggal 5 Nopember 2020 bertempat di Laboratorium Pertunjukan Teater Kecil Fakultas Seni Pertunjukan ISI Surakarta. Penelitian ini menggunakan data kualitatif yang menghasilkan data-data deskriptif. Model penelitian ini adalah deskriftif dengan studi kasus tata kelola pertunjukan tari dalam Ujian Tugas Akhir mahasiswa Program Studi S-1 Tari ISI Surakarta di Laboratorium Fakultas Seni Pertunjukan Teater Kecil ISI Surakarta.

Secara spesifik penelitian ini akan mendeskripsikan tata kelola pertunjukan tari di laboratorium seni pertunjukan yang mengedepankan sudut pandang dari manajemen. Definisi manajemen menurut James AF Stoner meliputi; perencanaan, pengorganisasian, kepemimpinan, dan pengendalian (Dadang Suganda, 2002: 20-21).

Selain itu, pengalaman empiris peneliti sebagai stage manager pada beberapa kegiatan pergelaran seni memberikan kontribusi dalam menjelaskan hal-hal yang bersifat teknis maupun non teknis secara detail. Menurut peneliti, bahwa pergelaran atau pertunjukan seni tidak hanya berbicara tentang manajemen saja tetapi juga tentang pendukung karya, pencipta karya, dan nilai estetik karya itu sendiri serta penonton.

Untuk memperlancar penelitian ini perlu dilakukan langkah-langkah penelitian pengumpulan dan analisis informasi. Data dan informasi didapatkan dari sumber-sumber pustaka. Sumber pustaka atau manuskrip yang berhubungan dengan ilmu manajemen, terutama manajemen seni pertunjukan. Kemudian bukubuku yang berhubungan dengan penciptaan karya (tari), misalnya tentang koreografi, skenografi, tata panggung (artistik), proses produksi teater, proses produksi TV dan Film.

Data serta informasi yang didapat penulis kemudian di kelompokan berdasar kategori masing-masing kemudian dilakukan proses analisis. Proses analisis ini di antaranya adalah penyesuaian data dengan konten tema penelitian. Data awal dan memerlukan penafsiran ulang. Penafsiran ulang ini berguna untuk penyesuaianpenyesuaian berkaitan dengan konten, baik itu secara teknis maupun pemaknaan.

Proses untuk menentukan kesimpulan menunggu sampai proses pengumpulan data, penafsiran, proses penulisan selesai.

\section{Hasil Dan Pembahasan}

\section{Peran Manajemen Pertunjukan}

Manajemen adalah satu bentuk kerja. Manajer dalam melakukan pekerjaannya, harus melaksanakan kegiatan-kegiatan tertentu, yang dinamakan fungsi-fungsi manajemen. Menurut Terry dan Rue (M. Takari, 2008) ada lima fungsi utama manajemen, yaitu Perencanaan, Pengorganisasian, penentuan sumber daya, memotivasi, pengawasan (Muhammad Takari, 2008: 44-45).

Fungsi manajemen menurut Dadang Suganda (2008) hampir senada yang diunagkapan di atas, hanya membaginya menjadi empat, yaitu perencanaan, pengorganisasian, kepemimpinan, pengawasan.

a. Planning atau perencanaan, yaitu menentukan tujuan yang hendak dicapai dan membuat 
rencana kegiatan untuk mencapai tujuan.

Perencanaan merupakan fungsi utama dari manajer. Pelaksanaan kegiatan tergantung kepada perencanaan.

Jenis-jenis perencanaan di antaranya ialah: perencanaan fisik, perencanaan fungsional, dan perencanaan komprihensif. Perencanaan fisik meliputi perencanaan yang sifatnya fisik, seperti gambar atau layout panggung pertunjukan (lihat gambar 1). Perencanaan fungsional berkaitan dengan perencanaan yang sifatnya fungsional, seperti perencanaan produksi, perencanaan keuangan, perencanaan penjualan, perencanaan advertensi, dan lainnya.

Perencanaan komprehensif merupakan gabungan antara perencanaan fisik dan perencanaan fungsional. Dalam perencanaan harus memasukkan anggaran (budget) yang disesuaikan dengan kemampuan finansial.

b. Organizing atau pengorganisasian, adalah mengelompokkan dan menentukan berbagai kegiatan.

Proses pengelompokkan kegiatan ini untuk mencapai tujuan dan penugasan setiap kelompok kepada seorang manajer. Dalam pengorganisasian ini ada lima aspek yang penting yaitu: (1) tujuan yang akan dicapai, (2) penetapan dan pengelompokkan pekerjaan, (3) wewenang dan tanggung jawab, (4) hubungan satu sama lainnya, dan (5) penetapan orang-orang yang akan melakukan tugasnya.

c. Leadership atau kepemimpinan mencakup dua hal yaitu staffing atau penentuan sumber daya manusia yaitu menentukan keperluan-keperluan sumber daya manusia, pengerahan, penyaringan, latihan, dan pengembangan tenaga kerja dan motivating, yaitu mengarahkan atau menyalurkan perilaku manusia ke arah tujuan-tujuan yang hendak dicapai.

Penentuan sumber daya adalah pentingnya menempatkan orang yang tepat yang sesuai dengan bidang pekerjaan. Kualitas pekerja ini yang menjadi salah satu penentu keberhasilan organisasi.

Seorang pemimpin dituntut dapat mengarahkan anak buahnya untuk melakukan tugas-tugasnya dengan baik. Artinya pemimpin akan menggerakan, membangkitkan, dan mendorong semua anggota kelompok agar berusaha dengan segenap kemampuannya untuk mencapai tujuan yang telah direncanakan.

Aspek yang penting dalam pengerakan manajemen adalah supervise. Kegiatan ini dilakukan saat pekerjaan sedang berlangsung oleh manajer. Aspek disiplin sangat penting dalam rangka penggerakan ini. Disiplin adalah suatu keadaan tertib, di mana orang-orang yang tergabung dalam sebuah organisasi tunduk pada peraturan yang ada dan telah disepakati, dengan rasa senang hati. Disiplin ini dipicu oleh dua faktor, yaitu disiplin yang timbul dari dalam dirinya sendiri dan disiplin karena perintah dari luar dirinya. Mengingat penggerakan dalam sistem manajemen tergantung seluruhnya pada manajer yang rasional dan kapabel.

d. Controlling, atau pengawasan, yaitu kegiatan dalam bentuk mengukur pelaksanaan sesuai dengan tujuan-tujuan, menentukan sebabsebab penyimpangan-penyimpangan dan mengambil tindakan-tindakan korektif yang diperlukan.

Pengawasan adalah kegiatan mengecek atau mengatur seperti pembayaran, menyesuaikan dengan batas-batas seperti kecepatan, serta menguji atau memeriksa dengan bukti atau pengalaman yang sama atau sebaliknya. Pengawasan ini juga berarti wewenang untuk membimbing atau memerintah yang di dalamnya tercakup makna pembimbingan, penertiban, pengaturan, pemeriksaan, dan pengendalian.

Agar pengawasan lebih efektif, maka harus ditetapkan prinsip-prinsip pengawasan, yang terdiri dari: (1) prinsip tercapainya 
tujuan, (2) prinsip efisiensi pengawasan,

(3) prinsip tanggung jawab pengawasan,

(4) prinsip pengawasan terhadap kegiatan yang berlangsung, (5) prinsip pengawasan langsung; (6) prinsip refleksi pelaksanaan, (7) prinsip penyesuaian dengan organisasi, (8) prinsip kemandirian pengawas, (9) prinsip standar, (10) prinsip pengawasan terhadap faktor strategis, (11) factor pengecualian, (12) prinsip daya susuai pengawasan, (13) prinsip peninjauan kembali, (14) prinsip tindakan.

Proses Manajemen Panggung dalam pertunjukan Tugas Akhir S-1 Pementasan KaryaTari.

Seorang stage manager secara teknis dalam proses kegiatan pementasan tugas akhir pertunjukan tari ini melaksanakan prinsip-prinsip manajemen dalam pementasan yang dapat diuraikan sebagai berikut.

a. Perancangan

Stage Manager membuat denah pertunjukan yang akan digunakan untuk pertunjukan karya-karya tari. Denah ini diberikan kepada semua penyaji agar dapat dipergunakan untuk merancang blocking penari, blocking instrument music, setting/property, dan lain-lain.

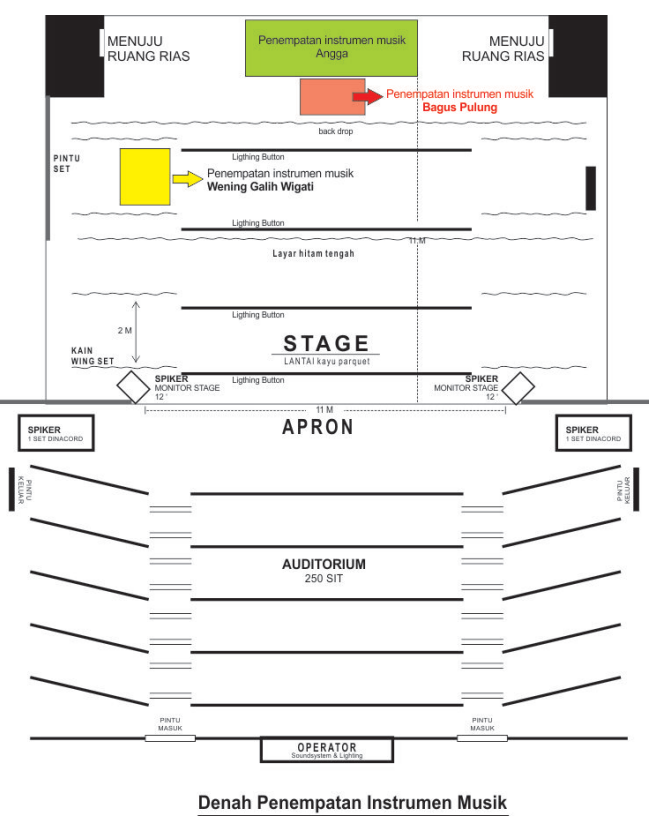

Gambar 1: Penempatan instrument music untuk ketiga penyaji
Daftar instrument music masing-masing penyaji.

1) Galuh Angga Pamutra menyajikan karya tari "Megatruh". Instrument musiknya Gamelan Slendro terdiri dari:
a) Bonang Barung
b) Bonang Penerus
c) Gender
d) Slenthem
e) Saron
f) Demung
g) Peking
h) Kenong
i) Gong dan Kempul
j) Rebab
k) Vokal

2) Wening Galih Wigati, judul karya tari "Sabet". Instrument music adalah:
a) Bonang Barung Pelog
b) Kendang Surabayan
c) Bedug (dol)
d) Terbang
e) Kenthongan
f) Gong dan Kempul
g) Terompet Madura
h) Vokal

3) Bagus Pulung, judul karya tari "Kedanan Ndadi”. Instrument music adalah:
a) Bonang Barung pelog-slendro
b) Bonang Penerus pelog-slendro
c) Kethuk
d) Bendhe
e) Kendang Sabet
f) Kendang Gede
g) Perkusi
h) Senar Drum
i) Tambur
j) Gong-kempul Pelog slendro
k) Gong Beri
I) Terompet
m) vokal

Stage Manager juga merencanakan kegiatan persiapan, gladi bersih, dan ujian pementasan dalam rundown yang dibagikan ke semua 
penyaji baik rundown set-up, gladi bersih dan pementasan.

b. Pengorganisasian

Proses ini dimulai sejak ditetapkannya namanama mahasiswa yang akan maju ujian tugas akhir penciptaan tari dan kepenarian oleh Prodi Tari. Kemudian Prodi Tari berkirim surat ke Fakultas Seni Pertunjukan untuk penyelenggaraan ujian tugas akhir dan permohonan untuk menggunakan laboratorium sebagai tempat penyelenggaraan pementasan. Perwakilan mahasiswa penyaji berkoordinasi dengan Kepala Laboratorium Fakultas Seni Pertunjukan terkait penggunaan gedung dan jadwal pementasan dan menunjuk stage manager yang akan melaksanakan pertunjukan ini. Stage manager kemudian membentuk tim dan langsung melakukan pekerjaannya. Tim yang dibentuk oleh stage manager melibatkan penata artistic dari ketiga penyaji, tim teknis laboratorium, dan kru yang bertugas membantu stage manager (gambar: 2).

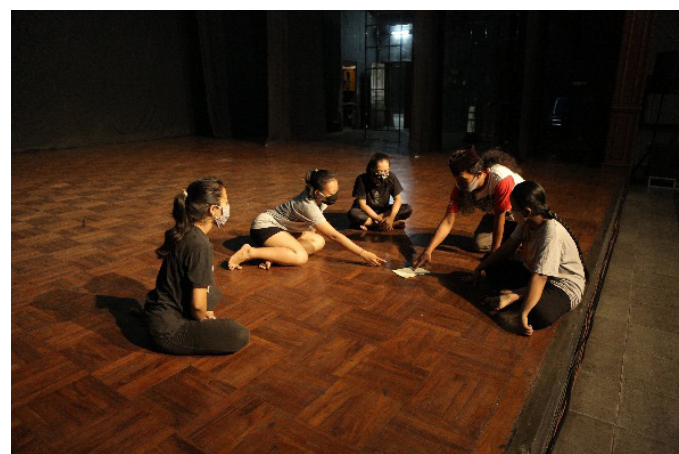

Gambar 2 : Koordinasi stage manager dengan tim penyaji (foto: Fery).

c. Kepemimpinan

Stage manager memimpin seluruh aktivitas teknis mulai dari persiapan, penataan (setting, lighting, soundsystem), mengatur penonton, pelaksanaan pertunjukan hingga akhir pertunjukan. Kedisiplinan stage manager akan berpengaruh pada kinerja tim teknis dan penyaji karya. Sehingga rundown yang telah dibuat dan disepakati bersama menjadi panduan untuk melaksanakan tugas sesuai bidang masing-masing (Gambar 3 dan 4).

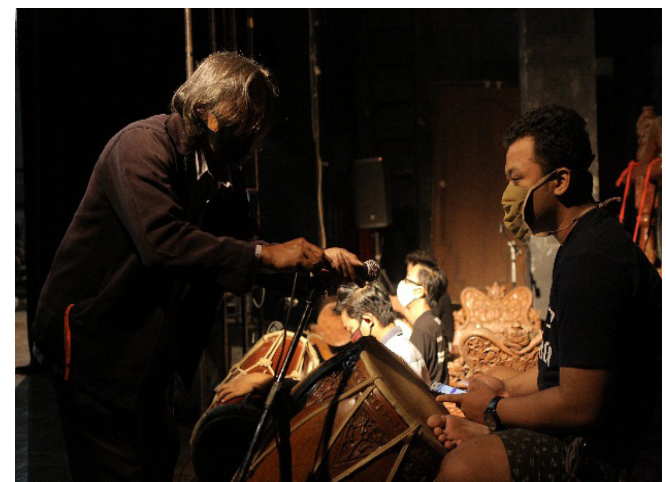

Gambar 3: Proses penataan microphone untuk instrument music (Foto: Fery).

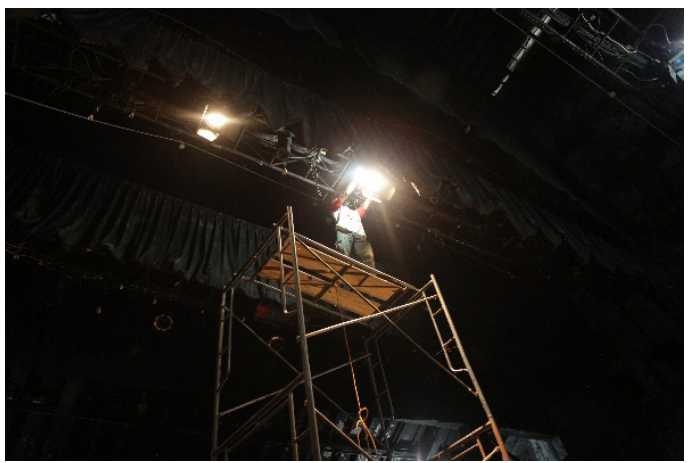

Gambar 4 : Penataan dan focusing lighting (Foto: Fery).

d. Pengawasan

Pengawasan dalam sistem manajemen untuk pertunjukan tugas akhir ini adalah mengetahui jalannya pekerjaan apakah lancar atau tidak, kemudian memperbaiki kesalahankesalahan dan mengusahakan pencegahan agar tidak terulang kembali, secara teknis tidak mengganggu konten pertunjukan (Gambar: 5).

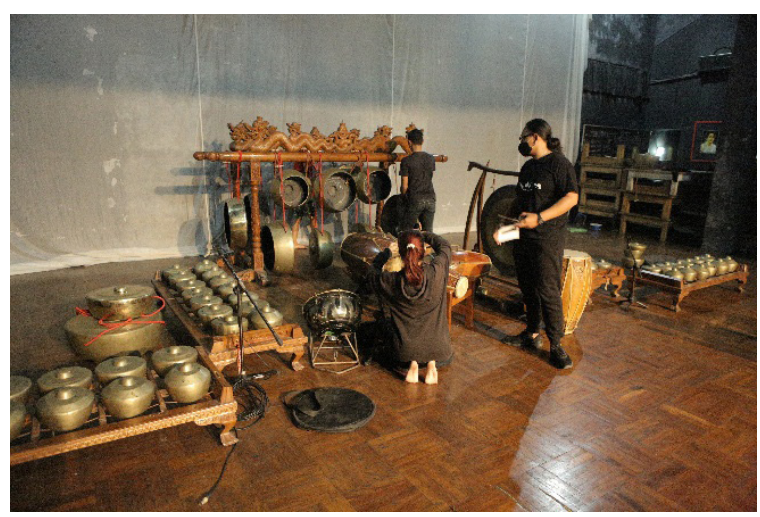

Gambar 5: Stage manager selalu hadir dan melakukan control setiap kali proses latihan agar mengurangi resika kesalah teknis (Foto: Fery) 


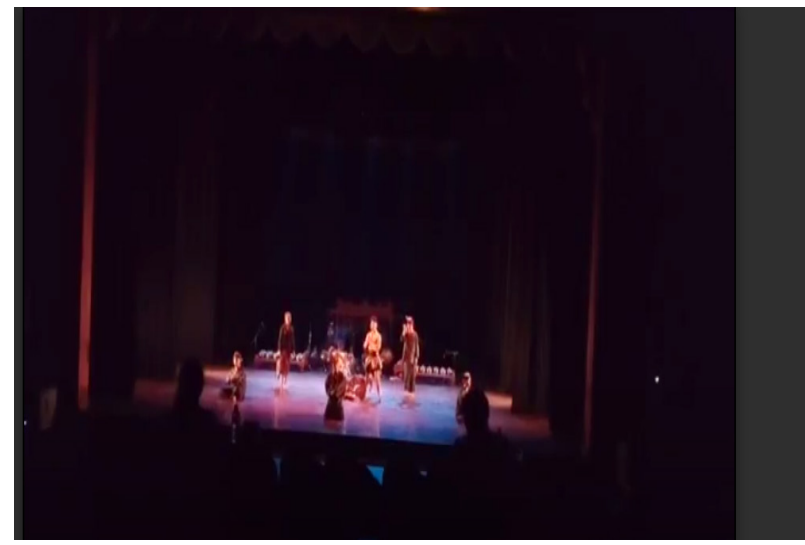

Gambar 6: Stage manager selalu hadir hingga sampai akhir pertunjukan (Foto: Fery)

\section{Kesimpulan}

Prinsip-prinsip manajemen mulai dari perencanaan, pengorganisasian, kepemimpinan, dan pengawasan yang di jalankan oleh stage manager telah memberikan bukti bahwa pertunjukan yang dikelolanya dapat berjalan dengan lancar dan sukses tanpa mengurangi nilai artistic bagi penyaji.

Pergelaran karya tari yang ditampilkan dalam ujian tugas akhir mahasiswa Program Studi S-1 Tari Jurusan Tari Fakultas Seni Pertunjukan ISI Surakarta tidak dapat dilepaskan begitu saja terhadap persoalan manajemen panggung. Justru dengan adanya manajemen panggung turut membantu proses pertunjukan menjadi lancar dan sukses.

Peran manajemen panggung yang diemban oleh stage manager yang diterapkan dalam proses yang baik dan benar turut membantu kelancaran pertunjukan. Peran inilah yang saat ini diemban oleh laboratorium pertunjukan Fakultas Seni Pertunjukan ISI Surakarta, tidak hanya melayani secara teknis tentang peralatan dan bahan untuk mendukung mahasiswa, dosen, dan civitas mahasiswa dalam ranah pendidikan, penelitian, dan pengabdian masyarakat tetapi juga dalam pengelolaan pertunjukan dari awal hingga selesai.

\section{Daftar Pustaka}

Dadang Suganda, 2002. Manajemen Seni Pertunjukan. Bandung: STSI Press Bandung.

Hasibuan, Malayu S.P. 2007. Manajemen Sumber Daya Manusia. Jakarta: Bumi Aksara.

Muhammad Takari, 2008, Manajemen Seni. Medan: Studio Kultura Fakultas Sastra Universitas Sumatera Utara.

Padmodarmaya, Pramana, 1988. Tata dan Teknik Pentas. Jakarta: Balai Pustaka.

Soedarso SP. 2006. Trilogi Seni, Penciptaan Eksistensi dan Kegunaan Seni. Yogyakarta: Badan Penerbit ISI Yogyakarta.

Tim Penyusun. 2019. Panduan Tugas Akhir Fakultas Seni Pertunjukan. Surakarta: ISI Press, edisi IV tahun 2019. 